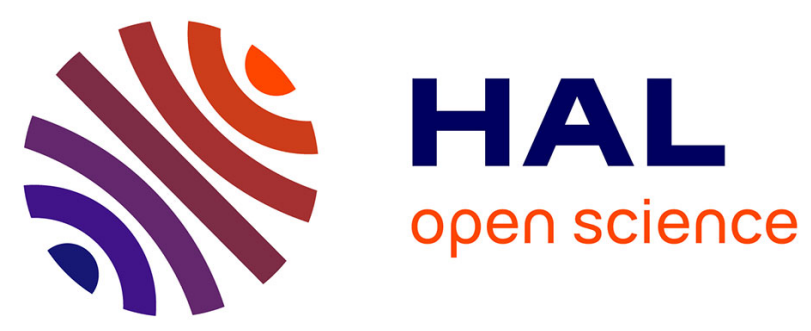

\title{
Flux Control Range Broadening and Torque Ripple Minimization of a Double Excitation Synchronous Motor
} Trung-Kien Hoang, L. Vido, M. Gabsi, F. Gillon

\section{To cite this version:}

Trung-Kien Hoang, L. Vido, M. Gabsi, F. Gillon. Flux Control Range Broadening and Torque Ripple Minimization of a Double Excitation Synchronous Motor. IEEE Transactions on Magnetics, 2017, 53 (1), pp.1 - 10. 10.1109/TMAG.2016.2616330 . hal-01657419

\section{HAL Id: hal-01657419 https://hal.science/hal-01657419}

Submitted on 6 Dec 2017

HAL is a multi-disciplinary open access archive for the deposit and dissemination of scientific research documents, whether they are published or not. The documents may come from teaching and research institutions in France or abroad, or from public or private research centers.
L'archive ouverte pluridisciplinaire HAL, est destinée au dépôt et à la diffusion de documents scientifiques de niveau recherche, publiés ou non, émanant des établissements d'enseignement et de recherche français ou étrangers, des laboratoires publics ou privés. 


\title{
Flux Control Range Broadening and Torque Ripple Minimization of a Double Excitation Synchronous Motor
}

\author{
K. Hoang ${ }^{1}$, L. Vido ${ }^{2}$, M. Gabsi ${ }^{1}$, and F. Gillon ${ }^{3}$ \\ ${ }^{1}$ Systèmes et Applications des Technologies de l'Information et de l'Energie (SATIE), École normale \\ supérieure de Cachan, 94235 Cachan, France \\ ${ }^{2}$ Systèmes et Applications des Technologies de l'Information et de l'Energie (SATIE), Universite \\ de Cergy-Pontoise, 95000 Cergy-Pontoise, France \\ ${ }^{3}$ Laboratoire Energétique, Electronique et Procédés (L2EP), Ecole Centrale de Lille, 59650 Villeneuve d'Ascq Cedex, France
}

\begin{abstract}
This paper presents performance improvements of a double excitation synchronous motor by using a reluctance network (RN). The distinguishing feature of the double excitation principle is to use permanent magnets with high energy, while air-gap flux is flexibly controlled by field windings. Therefore, the first contribution of this paper focuses on maximizing air-gap flux range control. Second, an approach for torque ripple reduction is proposed by directly modifying air-gap flux according to the instantaneous torque profile. The achieved resultant torque stays almost constant for a case study. The validity of the RN method is examined by comparisons with 3-D finite element and experimental results for several machines.
\end{abstract}

Index Terms-3-D modeling, air-gap flux control, double excitation, reluctance network (RN), synchronous motor.

\section{INTRODUCTION}

A DOUBLE (or hybrid) excitation synchronous motor (DESM) is constructed based on a combination between a permanent magnet synchronous motor (PMSM) and additional field windings [1]-[3]. The purpose behind is to bring together advantages of a PMSM, which is high power density and high efficiency and the good field weakening control capability of a wound field synchronous motor. Several papers have been presented focusing on DESMs. Amara et al. [1] covered basics of DESMs and also proposed a solution to improve the energy efficiency of the traction motor in electric or hybrid vehicle applications. Vido et al. [4] demonstrated different DESM topologies with homopolar and bipolar configurations. Nedjar et al. [5] presented a parallel type of DESM and comparisons with other structures.

In a DESM, two field flux sources are presented. One, which is almost constant, is produced by PMs. The other is controllably produced by one or more field windings. These two flux sources converge in the air gap. The air-gap flux is manipulated by controlling the field current. It is, therefore, desirable to improve flux range control of the machine, i.e., a same amount of field current could better increase or decrease air-gap flux. In addition, as a result of the direct airgap flux control, torque ripple could be minimized because of a proper field current pattern according to the instantaneous torque profile. The work of this paper is dedicated to the improvement of these two performances.

With field flux coming from two sources, the motor flux lines are truly 3-D in certain configurations [1]. As a result, high accuracy result should be necessarily obtained by using

Manuscript received April 13, 2016; revised August 16, 2016; accepted October 4, 2016. Date of publication October 11, 2016; date of current version December 20, 2016. Corresponding author: K. Hoang (e-mail: thoang@satie. ens-cachan.fr)

Color versions of one or more of the figures in this paper are available online at http://ieeexplore.ieee.org.

Digital Object Identifier 10.1109/TMAG.2016.2616330 the 3-D finite element method (3-D FEM). However, the inherited problem with 3-D FEM is time consuming [6], [7], especially in the early design stage when repetitive evaluations are essentially required.

In order to overcome this obstacle, a reluctance network (RN) method provides an alternative solution, which excellently dominates 3-D FEM regarding the computation time. An RN method is widely employed in the electric motor analysis, for example, switched reluctance motors [8], an induction motor [9], and an PM motor [10]. Using RN method is also advantageous compared with the FEM, when there is a need to couple with other analyses, such as thermal or acoustic ones [11]. In this paper, a lumped parameter RN method will be used to analyze and improve performances of a DESM. A crucial component of the RN model is the airgap reluctance that changes according to the relative positions between stator and rotor [12]. The work of this paper takes into account fringing flux paths in the air gap.

The content this paper is proceeded as follows. Section II presents the RN method with a DESM, and the validity of the method is verified with 3-D FEM and experiments. Section III proposes a structure to maximize flux control range using parametric design, and an approach to minimize torque ripple will be also introduced in this section. The conclusion and the perspective for the future work are discussed in Section IV.

\section{Reluctance Network Method With Desm}

\section{A. DESM Model Configuration}

A number of machine types using double principle have been realized according to different criteria. Regarding the type of flux combination, the motor could be classified as serial or parallel DESM. Concerning the localizations of the excitation flux sources, both sources could be placed in the stator, rotor, or mixed. Fig. 1 shows the DESM prototype [4].

For the purpose of clearance, distributed phase windings are not presented in Fig. 1. In this model, two global field 


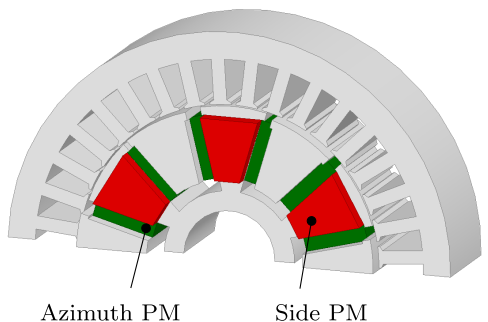

(a)

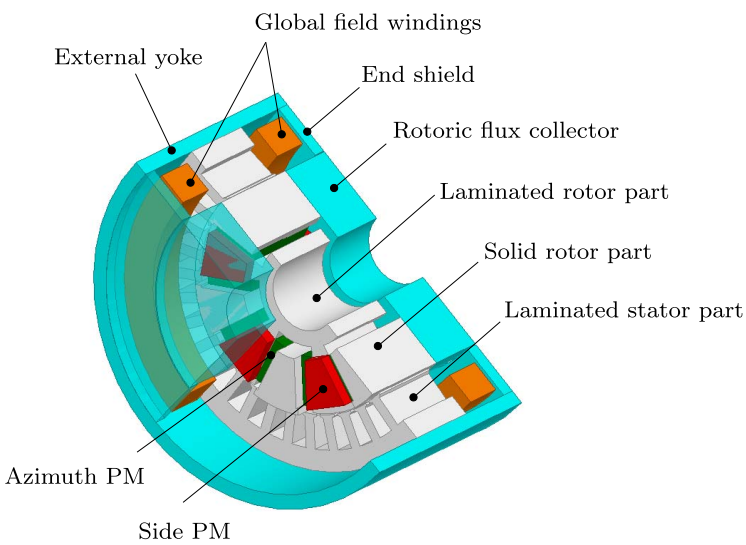

(b)

Fig. 1. DESM prototype used for analysis. (a) Arrangement of PMs. (b) 3-D model.

windings are located in the stator that helps to avoid sliding contacts. PMs are placed in the rotor using flux concentration principle to increase air-gap flux density. Due to this flux concentration, the prototype employs ferrite PMs, which are cheaper than rare earth counterparts. The stator uses conventional laminated core. However, on the account of 3-D flux paths presented in the rotor as in [4], both solid and laminated cores are used to construct this rotating part. The 3-D flux path characteristic also explains why 3-D FEM is necessary in the motor analysis. The configurations of the prototype are detailed in the Appendix.

\section{B. Lumped Parameter Reluctance Network}

Conventionally, there are two different methods that can be used with RN method, which are a tooth contour method [13] and a flux tube method [14]. The latter one is used in this paper. The motor is decomposed into parts; each part is then lumped by a reluctance limited by a tube. The flux is considered constant inside the tube.

The basic expression for reluctance calculation of a flux tube is given by (1) [15], and the tube permeance is expressed as (2)

$$
\begin{aligned}
& R=\int_{0}^{L} \frac{d l}{\mu_{0} \mu_{r} S(l)} \\
& P=\frac{1}{R}
\end{aligned}
$$

where $L$ is the tube length and $S$ is the cross section of the tube at position $l . \mu_{r}$ is the relative permeability of the tube material and $\mu_{0}$ is the permeability of the air. For the air and PMs, $\mu_{r}$ values are unity and for the core, $\mu_{r}$ is calculated according to nonlinear $B-H$ curve of the core material.

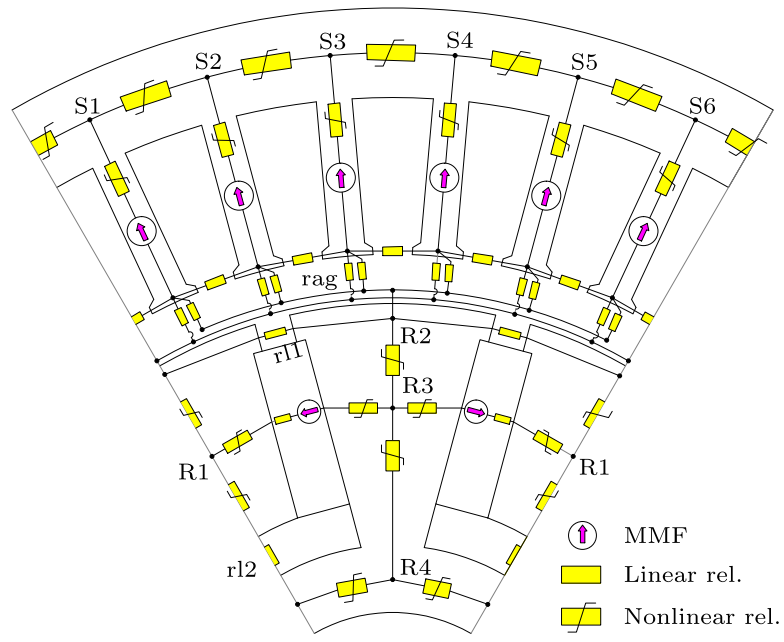

(a)

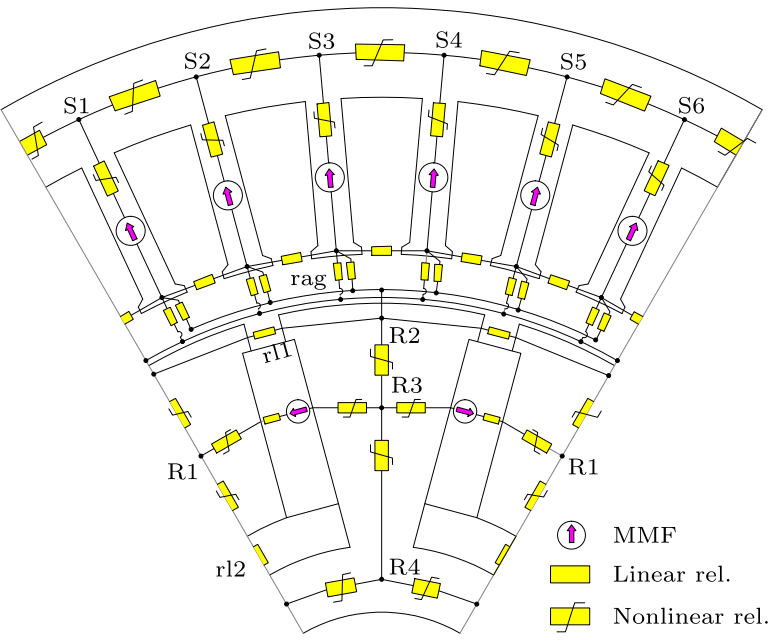

(b)
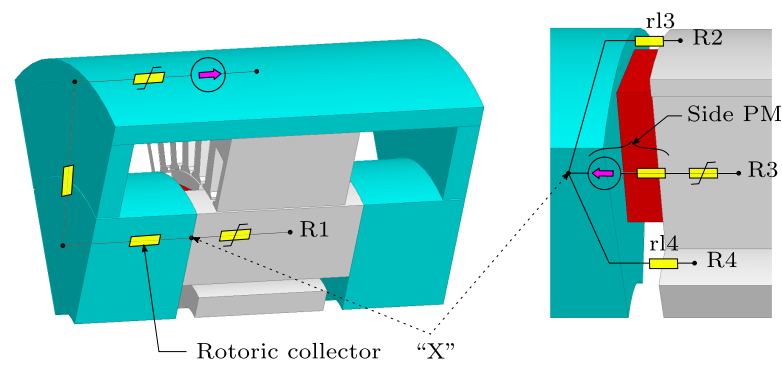

(c)

Fig. 2. RN model of the prototype. (a) First part. (b) Second part. (c) More details about elements in the axial direction.

A PM can be modeled by a reluctance connected in series with an equivalent MMF

$$
F_{\mathrm{PM}}=\frac{B_{r}}{\mu_{0}} h_{m}
$$

where $h_{m}$ and $B_{r}$ are the magnet thickness and residual flux density, respectively.

Fig. 2(a) and (b) shows the RN of the prototype defined for one pole pair. Elements in Fig. 2(b) are more elaborated in Fig. 2(c). For the ease of observation, the air-gap length is exaggerated to be large. The total $\mathrm{RN}$ is divided into two parts, the first one [Fig. 2(a)] consists of laminated stator, 
laminated and solid rotor parts, phase windings, and azimuth magnets. The second part is composed of two field windings, side magnets, external yoke, rotoric flux collectors, and end shields [Fig. 2(b)]. The function of the second part is to conduct the flux in the third dimension. This flux strategy starts from the stator, going through the air-gap reluctance [rag - Fig. 2(a)], and then passing through the side PMs, a rotoric collector, outer air-gap reluctance [rag0 - Fig. 2(b)], an end-shield, and returning to the stator. Due to the symmetrical geometry of the motor in axial direction, Fig. 2(b) shows only one side of the second part, the other side is exactly the same. The number of reluctances presented in the stator is actually bigger than the ones for rotor and other parts (rotoric collector, end shield, and external yoke parts), and this can be explained by flux density variation differences across the stator. In contrast, the rotoric collectors as well as the rotor part are not saturated due to their big volumes, and a minor flux density variation is also reported. That explains a small number of nodes presented in these regions, and even a linear material could be proposed here without a big influence in the whole model. This phenomenon will be reported elaborately in Section II-C with 3-D FEM.

An MMF source placed in the stator tooth is linearly combined from ones separately created by phase coils. An MMF created by one phase coil is given in the following:

$$
F_{c}=i N_{c}
$$

where $i$ and $N_{c}$ are current and number of turns of the phase coil.

Due to iron parts above and below the PMs, the PMs flux leakages are expected to be high. $r l 1$ and $r l 2$ in Fig. 2(a) account for flux leakages of azimuth PMs in both the upper and lower areas of these PMs. $r l 3$ and $r l 4$ in Fig. 2(b) are for flux leakages of side PMs in both the upper and lower areas. These leakages are of importance to consider because of their weakening effects on the air-gap flux generated by PMs.

In the RN, the complexity and computation time generally depend on numbers of reluctances and nodes. In this paper, the model consists of 24 nodes with 44 nonlinear reluctances (core material) and 34 linear reluctances (air-gap and PM reluctances). Most of the reluctances can be easily calculated based on the element shapes. However, elaborate consideration should be taken for air-gap reluctances [rag in Fig. 2(a)]. The difficulty is due to complex flux fringing paths. Moreover, these reluctances depend on the rotor's angular positions.

In this model, each stator tooth is connected to both rotor poles by two corresponding reluctances. In a simplest manner, the air-gap flux is assumed to be confined within the overlapped area between stator tooth and rotor teeth, however, a big error would occur due to fringing effect, i.e., the overlapped area must be extended.

Zhu et al. [16] have simplified these complex fringing paths by considering equipotential assumptions on stator and rotor surfaces, and flux paths are perpendicular to the tooth surfaces. By this assumption, tangential air-gap flux densities are neglected. Some typical flux paths are shown in Figs. 3 and 4, which show three different types of flux path used for calculations in this paper.

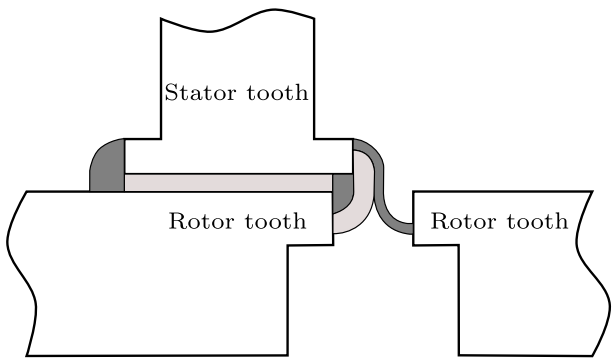

Fig. 3. Illustration for fringing flux consideration.

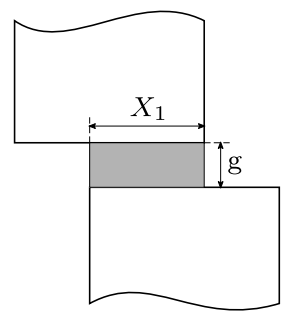

(a)

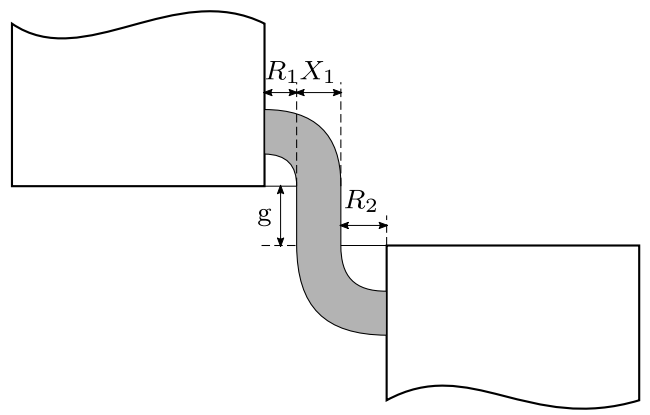

(c)

Fig. 4. Typical air-gap flux tube shapes. (a) Rectangle. (b) Rectangle with one quarter-annulus. (c) Rectangle with two quarter-annuli.

Air-gap permeances in Fig. 4 for cases (a), (b), and (c) are given by (5) in that order

$$
\begin{aligned}
& P^{(\mathrm{a})}=\frac{\mu_{0} L_{a} X_{1}}{g} \\
& P^{(\mathrm{b})}=\frac{2 \mu_{0} L_{a}}{\pi} \ln \left(1+\frac{\pi X_{1}}{\pi R_{1}+2 g}\right) \\
& P^{(\mathrm{c})}=\frac{\mu_{0} L_{a}}{\pi} \ln \left(1+\frac{2 \pi X_{1}}{\pi\left(R_{1}+R_{2}\right)+2 g}\right)
\end{aligned}
$$

where $L_{a}$ is the axial length of the stator tooth.

The air-gap permeance (between one stator tooth and rotor over one pole pair) is shown in Fig. 5. The air-gap permeance is maximum when stator tooth is entirely overlapped by rotor pole and zero and when the stator tooth moves far away from rotor pole. As it can be seen in Fig. 5, smooth transitions between maximum and zero permeance regions well reflect the consideration of flux fringing paths.

The nonlinear equations system for the nodal magnetic potential $u$ is given by the following:

$$
\left[\begin{array}{cccc}
P_{11} & P_{12} & \ldots & P_{1 n} \\
P_{21} & P_{22} & \ldots & P_{2 n} \\
\ldots & & & \\
\ldots & & & \\
P_{n 1} & P_{n 2} & \ldots & P_{n n}
\end{array}\right]\left[\begin{array}{c}
u_{1} \\
u_{2} \\
\ldots \\
\ldots \\
u_{n}
\end{array}\right]=\left[\begin{array}{c}
\phi_{1} \\
\phi_{2} \\
\ldots \\
\ldots \\
\phi_{n}
\end{array}\right]
$$




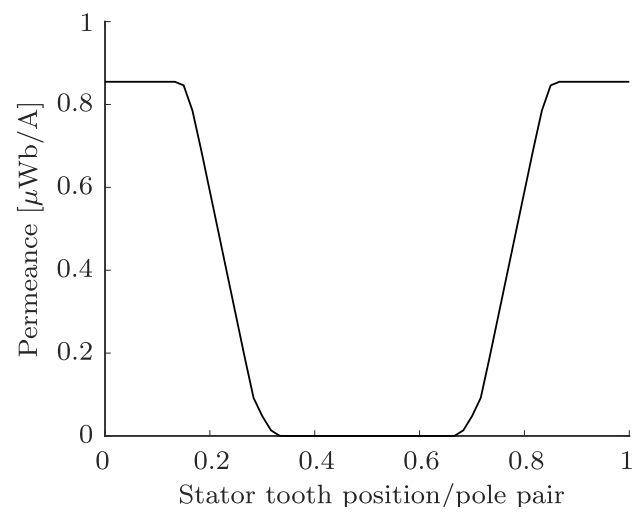

Fig. 5. Air-gap permeance between a stator tooth and a rotor pole.

with permeance matrix

$$
P_{i j}= \begin{cases}-p_{i j} & \text { if } i \neq j \\ \sum_{\substack{k=1 \\ k \neq i}}^{n} p_{i k} & \text { if } i=j\end{cases}
$$

and flux sources

$$
\phi_{i}=\sum_{\substack{k=1 \\ k \neq i}}^{n} F_{i k} p_{i k}
$$

where $n$ is the number of nodes, $p_{i j}$ is the permeance connection between nodes " $i$ " and " $j, " u_{i}$ is the scalar magnetic potential at node " $i$," and $F_{i k}$ is the magnetomotive force placed between nodes " $i$ " and " $k$." (6) is solved by an iterative process using fixed point method, as shown in Fig. 6. In this algorithm, core relative permeabilities are all initially assigned to 9000 . Permeabilities are recalculated based on magnetization curve of the core material. The stopping criteria target both permeability difference $\left\|\left(\boldsymbol{\mu}^{(k+1)}-\boldsymbol{\mu}^{(k)}\right) / \boldsymbol{\mu}^{(k)}\right\| \leq$ $1 \%$ and maximum number of iterations, which is 20 .

Permeabilities are recalculated based on newly updated field intensities $H$. In [17], relative permeability $\mu$ is presented as a function of $H$ expressed by the following:

$$
\mu(H)=\mu_{0}\left(1+\sum_{k=1}^{K} \frac{m_{k}}{b_{k}} \frac{\left|H / b_{k}\right|^{n_{k}-1}}{1+\left|H / b_{k}\right|^{n_{k}}}\right)
$$

where $K$ is the approximation order and $m_{k}, n_{k}$, and $b_{k}$ are fitting coefficients with the values detailed in the Appendix. By approximated function (9), the core permeability approaches $\mu_{0}$, when field intensity goes to infinity.

\section{Validation With FEM and Experimental Results}

In order to verify the accuracy and computation time of the RN method, the results are compared with 3-D FEM by Ansys Maxwell package as well as experiments. The computation is done for one pole pair of 60 mechanical degrees with a step of one mechanical degree. Flux density distribution by FEM is shown in Fig. 7. Due to the 3-D complex topology, some parts are hidden in Fig. 7 for the demonstrative purpose. The flux density map shows a very little flux variation in the rotor,

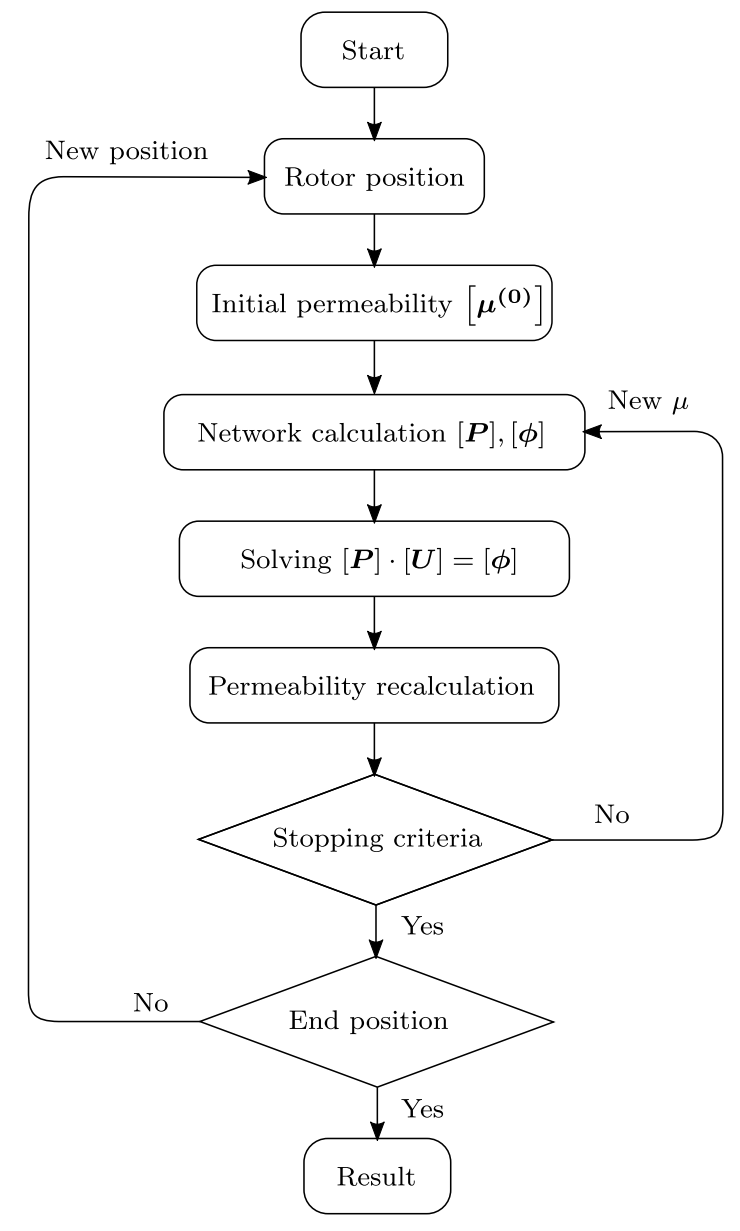

Fig. 6. Algorithm diagram for equation solving.

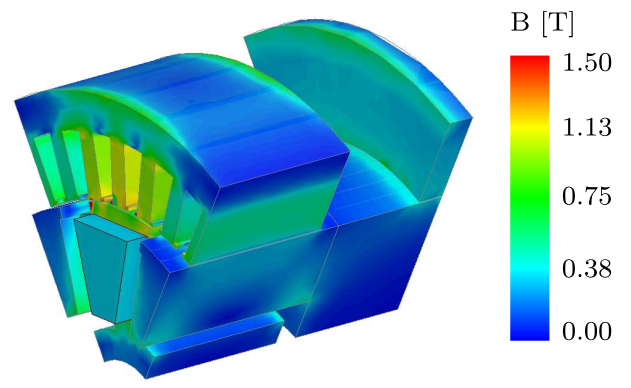

Fig. 7. No-load flux density distribution at aligned position. $I_{\mathrm{dc}}=0$ A.

rotoric collector, and end shield but a big difference in the stator. The stator teeth facing concentrated-flux path in the rotor is more saturated compared with others. Stator tooth flux densities with respect to rotor displacement are shown in Fig. 8.

In Fig. 8, the stator tooth starts from the point facing the non-concentrated-flux rotor tooth. Due to the homopolar configuration as in [4], the flux density waveform is not symmetric, where the stator tooth flux density gets higher when entering the concentrated flux area. This is also displayed in Fig. 7 with higher saturation for the stator teeth in the middle. The effects of field windings are not the same for these two areas, and less effect is seen in the concentrated flux area, where flux from field windings has to pass through 


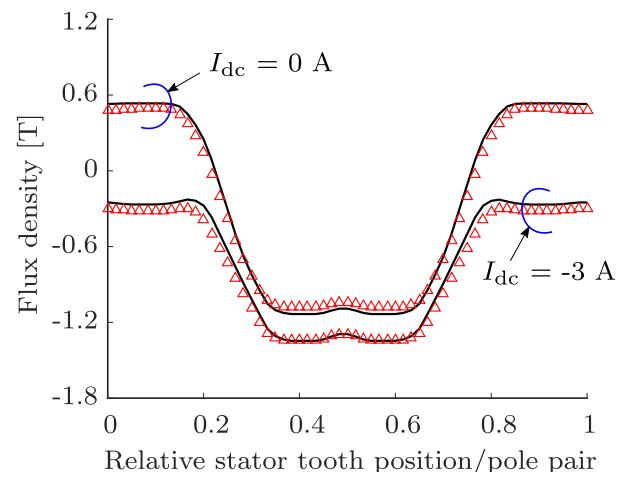

Fig. 8. Stator tooth flux density at no-load. Solid curve: RN method. Symbol: 3-D FEM.

TABLE I

Number of ElEMENTS AND COMPUTATION TIME COMPARISONS

\begin{tabular}{lll}
\hline & Number of elements & Time/point \\
\hline RN method & 24 nodes, 78 reluctances & $\approx 0.01 \mathrm{~s}$ \\
3D FEM & $\approx 60000$ & $\approx 64 \mathrm{~s}$ \\
\hline
\end{tabular}

side PMs to close the flux paths, and this is not the case for the non-concentrated flux area.

Table I summarizes comparisons on average between RN method and 3-D FEM in terms of problem size and computation time.

1) Phase Flux Linkage and Back EMF: Phase flux linkages $\lambda$ could be predicted directly by solving (6), and phase backEMFs are determined from the derivatives of phase flux linkages with respect to the time

$$
e=-\frac{d \lambda}{d t} \text {. }
$$

Flux linkage at no-load condition and back EMF comparisons are shown in Figs. 9 and 10, respectively. Flux weakening is tested by injecting a negative field current of $-3 \mathrm{~A}$. As it can be seen, good accordance is achieved.

2) Torque Calculation: In this paper, torque is calculated based on virtual work principle, which uses energy variation stored in the area enclosed by the flux and MMF [18], [19]. The mean torque is given in the following:

$$
T=m p \frac{\Delta W}{2 \pi}
$$

where $m$ is the number of phases, $p$ is the number of pole pairs, and $\Delta W$ is the co-energy converted per phase over an electrical period.

Fig. 11 shows torque generation as a function of phase current; field windings are not excited. The phase angle between phase current and EMF is zero. Torque calculated by the RN method is well confirmed by 3-D FEM as well as experiment.

Generated torque is basically a function of phase current and phase shift angle between this current and back EMF. However, by means of double excitation, field windings provide one more possibility for torque control by adjusting air-gap flux. This feature leads to an opportunity to minimize

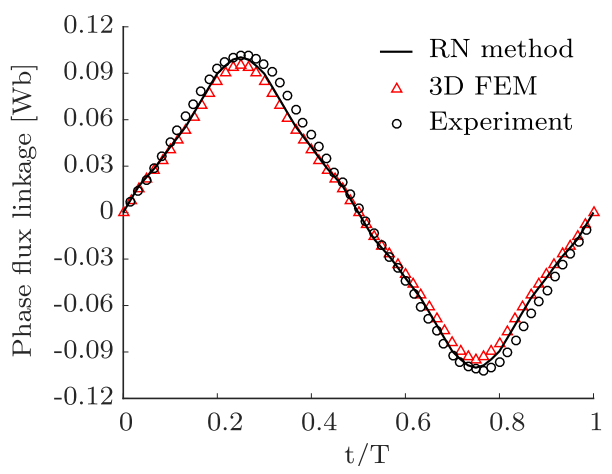

(a)

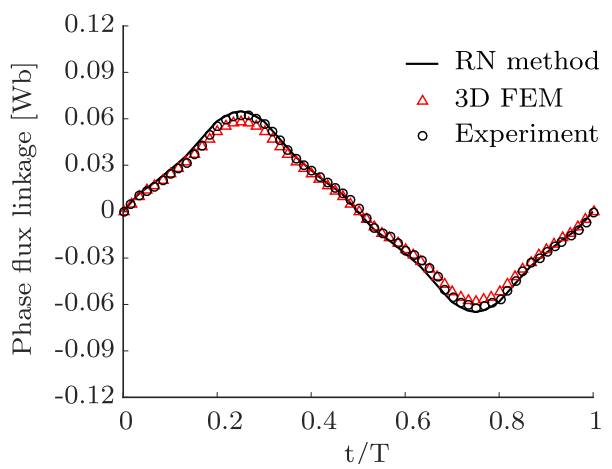

(b)

Fig. 9. No-load flux linkage comparisons. (a) $I_{\mathrm{dc}}=0$ A. (b) $I_{\mathrm{dc}}=-3 \mathrm{~A}$.

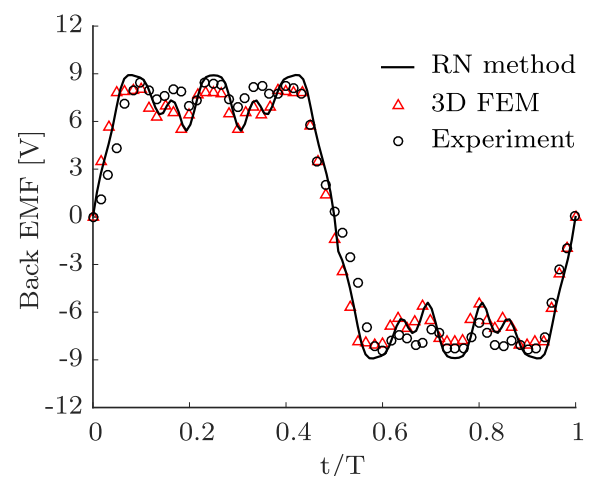

(a)

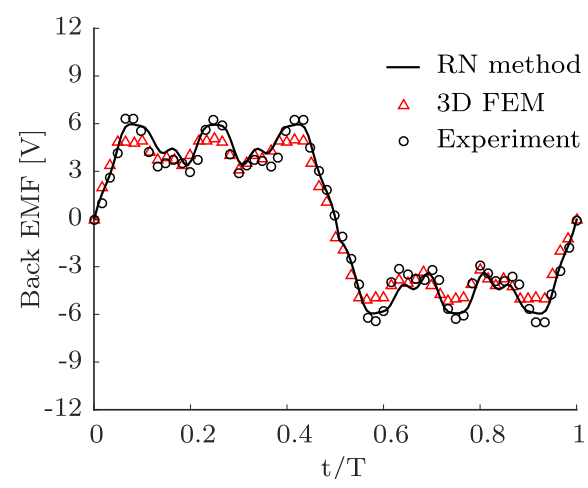

(b)

Fig. 10. Back EMF comparisons at $170 \mathrm{r} / \mathrm{min}$. (a) $I_{\mathrm{dc}}=0$ A. (b) $I_{\mathrm{dc}}=-3 \mathrm{~A}$.

copper loss while still attaining a required torque by a certain combination of phase and field currents. Fig. 12 shows the maximum torque for each combination of phase and field 


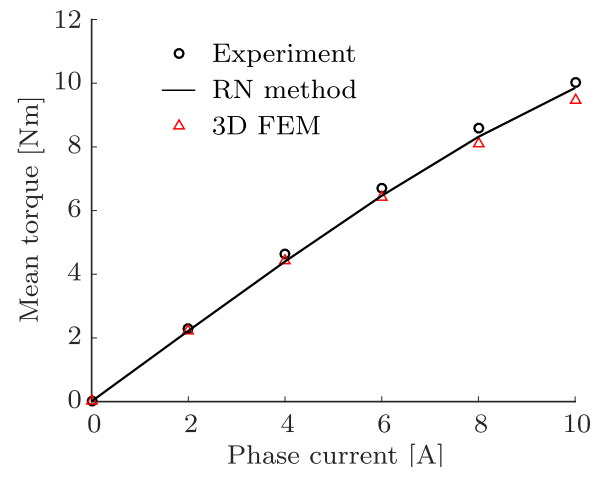

Fig. 11. Electromagnetic torque comparison with $I_{\mathrm{dc}}=0 \mathrm{~A}$.

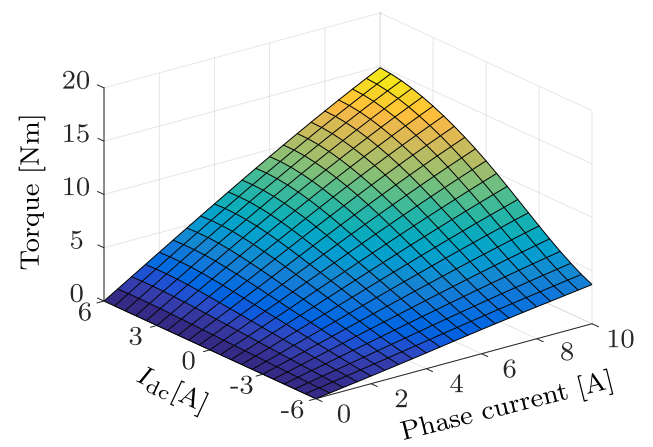

Fig. 12. Maximum torque according to the combination of field and phase currents.

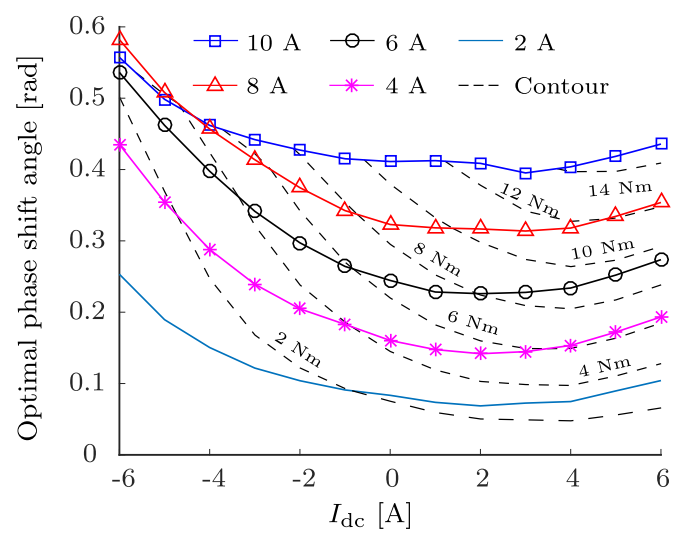

Fig. 13. Optimal phase shift angle according to field current at different phase currents $(2,4,6,8$, and $10 \mathrm{~A})$.

currents. (A simple optimization is performed to determine optimal phase shift angles.) Phase shift angle corresponding to the maximum torque should be ideally zero if saliency ratio is unity. However, due to the saliency, the generated torque is the sum of PM torque and reluctance torque leading to the variation of optimal phase shift angle depending on the portion of each type of torque. When phase currents are small in relative to field flux, the total torque is mainly due to electromagnetic torque. As phase current increases, reluctance torque utilization becomes more significant.

As will be seen in Fig. 13, phase shift angle tends to approach zero, when field current increases, i.e., more field flux increases when phase current increases.

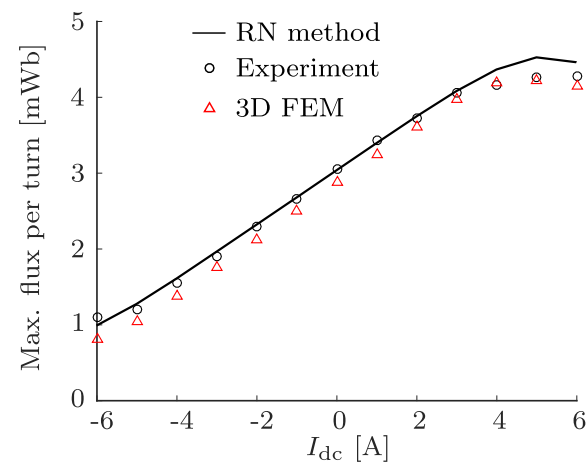

Fig. 14. Maximum flux per phase per turn at no-load.

The RN method applied to a prototype of DESM has been validated with the advantage of computation while maintaining good accuracy. In Section-III, this method will be exploited for the motor performance improvements.

\section{Prototype Performance Improvement With RN}

\section{A. Maximize Flux Control Range}

The obvious advantage of DESM is to increase the flux controlling flexibility either weakening or reinforcing air-gap field by injecting negative or positive field currents. In order to investigate this controlling capability, the maximum flux is determined over a wide range of field current, as shown in Fig. 14.

It is desirable to increase the slope of the flux versus field current curve, i.e., with the same amount of field current and effectively the same copper losses of the field windings, more air-gap flux is added (or reduced depending on the working mode). This characteristic is expressed by a factor $M_{\mathrm{dc}}$

$$
M_{\mathrm{dc}}=\frac{\Delta \lambda_{\max }}{\Delta I_{\mathrm{dc}}}
$$

where $\Delta \lambda_{\max }$ is the difference between two maximum flux linkages per turn due to field current difference $\Delta I_{\mathrm{dc}}$. In this case, $M_{\mathrm{dc}}$ values are $0.295,0.273$, and $0.272 \mathrm{mWb} / \mathrm{A} / \mathrm{turn}$ (calculated by RN method, 3-D FEM, and experiment, respectively). The higher value of $M_{\mathrm{dc}}$ reveals a better use of field current to control air-gap flux. A parametric study is conducted to examine the influence of geometry variables on $M_{\mathrm{dc}}$. Some variables expected to have clear influences are listed in Fig. 15(a) and Table II; detail results are shown in Fig. 15(b)-(f).

The parametric study approach is that at a time, only one parameter is varied while others stay unchanged as in the prototype (listed in the Appendix). Nine values equally distributed in the range of each variable will be examined.

A rough investigation on variable influences is described in the following.

1) End-Shield Thickness $x_{1}$ : This thickness would directly vary the contribution of field winding, since it affects strongly the magnetic reluctance paths of the field winding. 


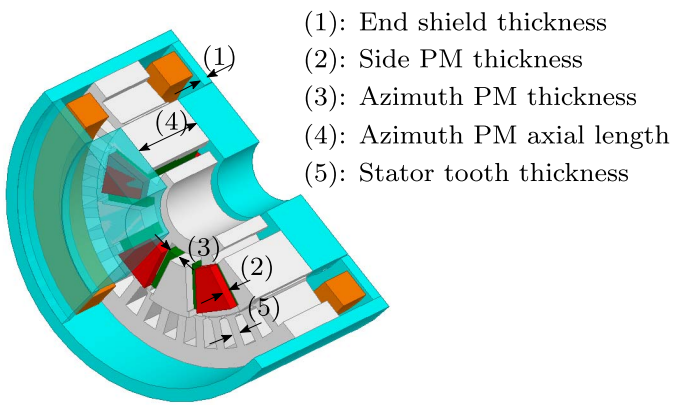

(a)

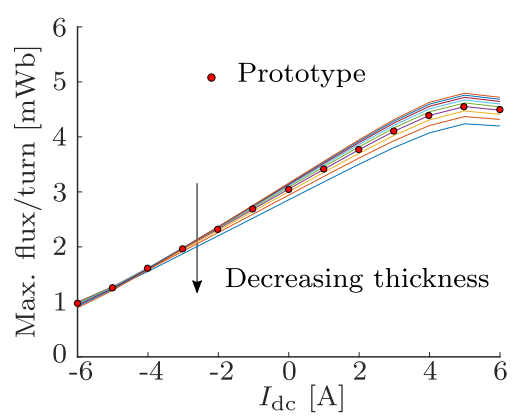

(d)

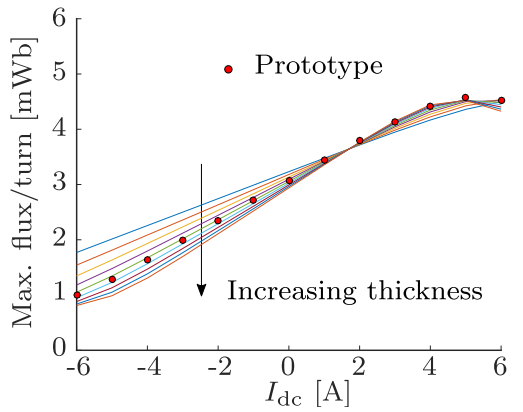

(b)

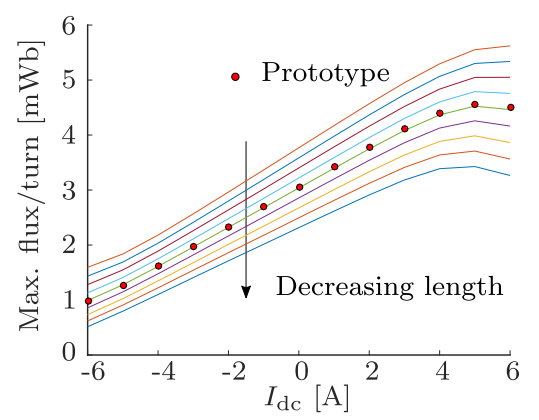

(e)

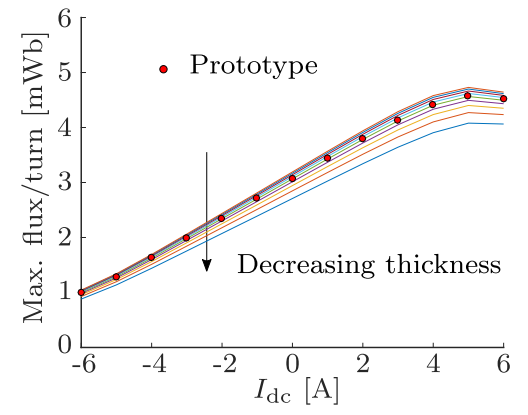

(c)

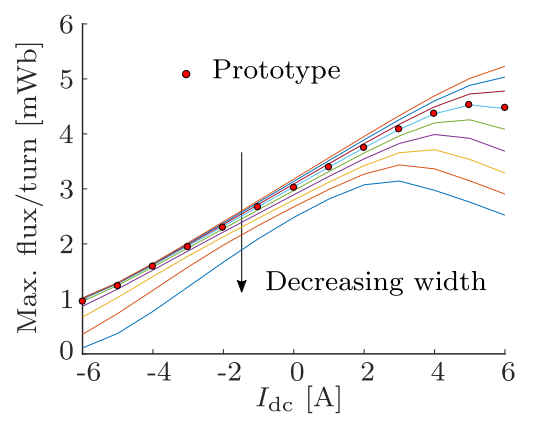

(f)

Fig. 15. Geometry variables and their influences on flux control range. (a) Geometry variables consideration. (b) Influence of $x_{1}$. (c) Influence of $x_{2}$. (d) Influence of $x_{3}$. (e) Influence of $x_{4}$. (f) Influence of $x_{5}$.

TABLE II

GeOMETRY VARiables FOR THE PARAMETRIC STUDY

\begin{tabular}{clll}
\hline Variable & Description & Range $[\mathrm{mm}]$ & Prototype $[\mathrm{mm}]$ \\
\hline$x_{1}$ & End-shield thickness & $3 \div 10$ & 7 \\
$x_{2}$ & Side PM thickness & $3 \div 10$ & 6 \\
$x_{3}$ & Azimuth PM thickness & $4 \div 10$ & 6 \\
$x_{4}$ & Azimuth PM axial length & $30 \div 50$ & 40 \\
$x_{5}$ & Stator tooth width & $3 \div 7$ & 5.5 \\
\hline
\end{tabular}

2) Side and Azimuth PM Thicknesses ( $x_{2}$ and $x_{3}$ ): These change the flux due to PMs and influence the portion of field winding contribution as a consequence.

3) Axial Length of the Azimuth PMs $x_{4}$ : This directly changes flux produced by PMs.

4) Stator Tooth Width $x_{5}$ : Changing this parameter will obviously vary the air-gap reluctance of the machine.

As can be seen in Fig. 15(b), increasing end-shield thickness will lower air-gap reluctance below the end-shields, and magnetic flux due to field winding will increase as a consequence. This effect means that flux portion due to field winding becomes more significant compared with one created by PMs making flux control easier. More effective flux from field windings also causes an early saturation, as seen in Fig. 15(b). The effect of PM thickness (both azimuth and side PMs) shown in Fig. 15(c) and (d) also once again reveals a complex magnetic flux paths of the machine [4], when there is actually a flux portion from field windings passes through PMs. Increasing PM thickness generally increases flux a bit but for this specific case, it will much increase magnetic reluctance path of flux from field winding. More flux from field winding, therefore, follows its expected direction (parallel to the flux produced by PMs). As shown in Fig. 15(c) and (d), a better characteristic is with thicker PMs. The influence of azimuth PM axial length is reported in Fig. 15(e), increasing this length makes flux portion by azimuth PM increases and total flux increases as well. However, this change will lessen saturation when field current reaches high. This is due to the fact that flux density contribution in the stator teeth by field windings is smaller when the azimuth axial length increases. Fig. 15(f) demonstrates the influence of stator tooth width. It should be noted that the stator tooth surface (with tooth tip) also decreases as stator tooth width decreases. Decreasing this width will increase air-gap reluctance, and total flux decreases. Magnetic saturation will also occur when the tooth is too narrow. The early saturation is due to the same reason as decreasing axial length of azimuth PM mentioned above (both make tooth surface lower and bigger portion of flux density due to field windings).

From these analyses, a combination of geometry variables is chosen to maximize flux control range by either increasing the upper point of the curve (point max) or decreasing the lower point of the curve (point $\mathrm{min}$ ).

1) $x_{1}=10 \mathrm{~mm}$ : Chosen with upper bound to decrease point min.

2) $x_{2}=7 \mathrm{~mm}$ and $x_{3}=7 \mathrm{~mm}$ : Chosen with upper bound to increase point max.

3) $x_{4}=50 \mathrm{~mm}$ : Chosen with upper bound to mainly increase point max.

4) $x_{5}=7 \mathrm{~mm}$ : Chosen with upper bound to mainly increase point max. 


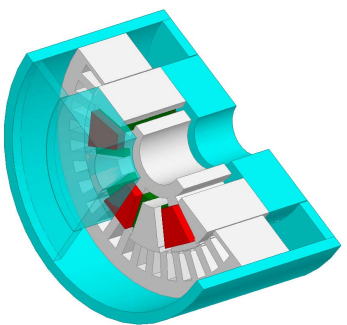

(a)

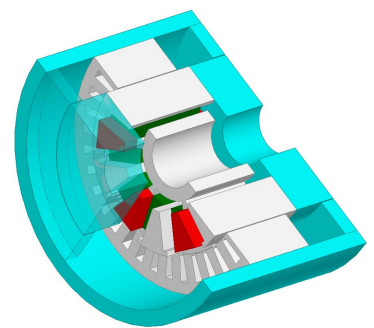

(b)

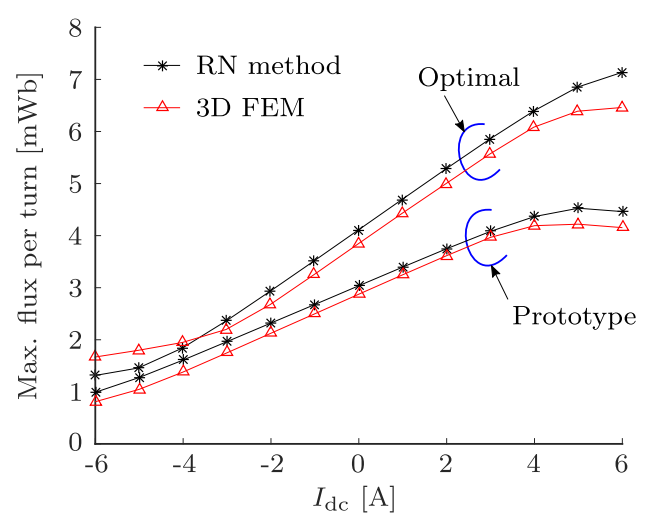

(c)

Fig. 16. DESM structures. (a) Prototype. (b) Optimal design. (c) Flux range control comparison.

The optimal design and the resultant flux range control are shown in comparison with that of the prototype in Fig. 16. By FEM calculation, the new design improves flux control range with $M_{\mathrm{dc}}=0.40$ compared with the one of 0.27 with the prototype.

\section{B. Torque Ripple Minimization of the Prototype}

As discussed, air-gap flux is effectively controlled by field windings, and a controllable torque would be expected. Fig. 12 partly showed the dependence of mean torque on field current. However, it would be more advantageous to apply flux control capability of field windings on the instantaneous torque. In this paper, an approach for constant torque scheme is proposed. This feature is quite desirable for the low speed region. The idea is to directly reduce or increase air-gap flux when instant torques are high or low, respectively. First, cogging torque and instant torque are showed in Fig. 17. Cogging torque is derived by using flux MMF diagram with PM, as in [19]. As will be seen, torque ripple is reported to be rather big, which is about $44.36 \%$ computed by FEM and $46.54 \%$ computed by RN method.

A case study is applied to the instant torque, as shown in Fig. 17, with the objective to minimize torque ripple while maintaining a mean torque of $8 \mathrm{Nm}$. The approach is detailed as follows.

1) Field Current Range: $I_{\mathrm{dc}}=-6 \mathrm{~A} \div 6 \mathrm{~A}$.

2) Phase current is kept sinusoidal with $10 \mathrm{~A}$ (rms) to improve some very low instant torque values in Fig. 17.

3) A phase angle is found to make sure that $8 \mathrm{Nm}$ is achievable at any rotor position with that phase angle.

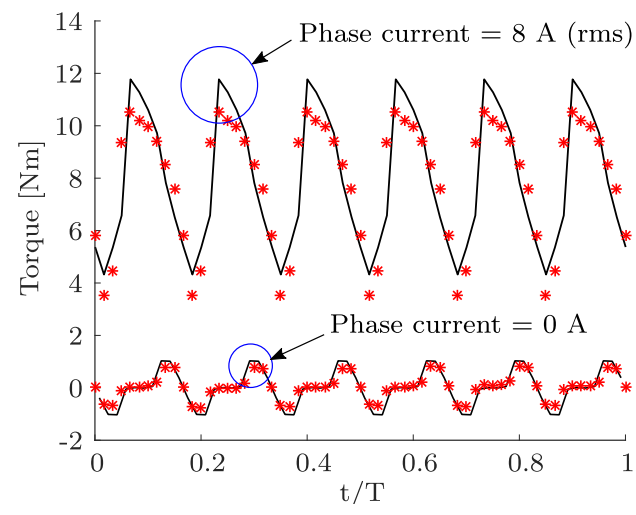

Fig. 17. Instant torque comparisons with $I_{\mathrm{dc}}=0$ A. Solid line: RN method. Symbol: 3-D FEM.
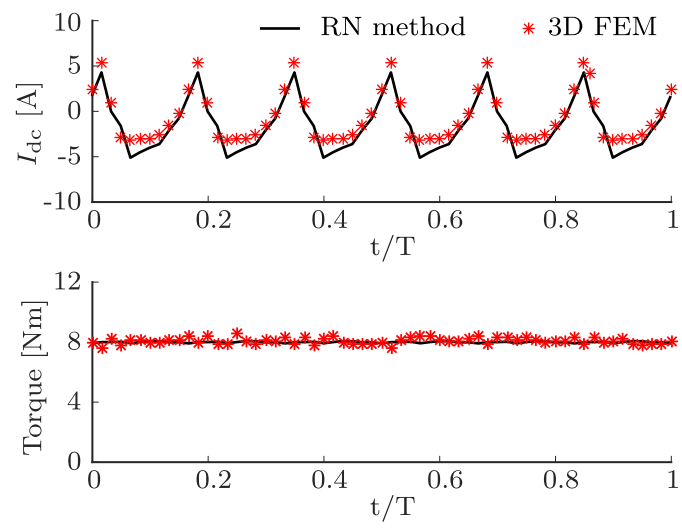

Fig. 18. Field current pattern and resultant torque comparisons.

4) When the phase angle has been found, at any rotor position, a field current is searched to make instant torque closest to $8 \mathrm{Nm}$.

5) The field current pattern is derived.

This approach is intended to highlight the contribution advantage of field current but not taking into account other factors, such as copper loss minimization or thermal aspect. Therefore, the chosen of $10 \mathrm{~A}$ phase current does not require a strict consideration, this value needs not too high to avoid using high field current to reduce instant torque at some points. In order to achieve the target, a parametric analysis will be used. The phase angle is found to be $0.57 \mathrm{rad}$, and result comparisons between RN method and FEM are shown in Fig. 18 with good accordance. The torque ripple is much reduced, which is $5.78 \%$ with FEM and $2.79 \%$ with $\mathrm{RN}$ method. The field current pattern reciprocally follows the trend of instant torque displayed in Fig. 17.

Field windings actually provide one more possibility to manipulate air-gap flux distribution to get the torque ripple minimized. It could be observed that the frequency of the requested field current is six times higher than that of current supplied to the phase winding. However, this is not a big challenge, since a low torque ripple is more desirable at low speed, i.e., power is supplied at low frequency. 
TABLE III

DESM PROTOTYPE CONFIGURATION

\begin{tabular}{ll}
\hline Parameters & Value \\
\hline Number of phases & 3 \\
Number of turns per phase & 33 \\
Number of turns per field winding & 150 \\
Number of poles & 12 \\
Motor length & $115 \mathrm{~mm}$ \\
Outer stator diameter & $92 \mathrm{~mm}$ \\
Inner stator diameter & $57.5 \mathrm{~mm}$ \\
Number of slots & 36 \\
Air-gap length & $0.5 \mathrm{~mm}$ \\
PM residual flux density & $0.4 \mathrm{~T}$ (ferrite PM) \\
\hline
\end{tabular}

TABLE IV

FitTING COEFFICIENTS FOR PERMEABILITy FunCtion $\mu(H)$ IN $(9)$

\begin{tabular}{llll}
\hline $\mathrm{k}$ & 1 & 2 & 3 \\
\hline$m_{k}\left(\times 10^{5}\right)$ & 4.53 & 5.60 & 3.50 \\
$n_{k}$ & 3.67 & 1.00 & 1.00 \\
$b_{k}$ & 46.52 & 105.78 & 600.00 \\
\hline
\end{tabular}

\section{CONCLUSION}

The analysis and performance improvements of a DESM have been realized by using the RN method. The flux control range of the machine was improved making the use of excitation current more effective, and hence, copper loss saving possibility due to this is very promising. In addition, torque ripples could be minimized by injecting appropriate excitation current patterns. This improvement is quite interesting to low speed applications. There is still future work to accomplish. First, a more deliberate analysis considering thermal aspect should be carried out, since field windings introduce a difficulty for heat evacuation. Second, in order to further examine the torque ripple reduction approach, the machine will be experimented with static tests with the excitation pattern, as shown in Fig. 18, and then dynamic tests at various speeds will be accomplished.

\section{APPENDIX}

See Tables III and IV.

\section{REFERENCES}

[1] Y. Amara, L. Vido, M. Gabsi, E. Hoang, A. H. Ben Ahmed, and M. Lécrivain, "Hybrid excitation synchronous machines: Energyefficient solution for vehicles propulsion," IEEE Trans. Veh. Technol., vol. 58, no. 5, pp. 2137-2149, Jun. 2009.

[2] J. A. Tapia, F. Leonardi, and T. A. Lipo, "Consequent-pole permanentmagnet machine with extended field-weakening capability," IEEE Trans. Ind. Appl., vol. 39, no. 6, pp. 1704-1709, Nov. 2003.

[3] J. S. Hsu, "Direct control of air-gap flux in permanent-magnet machines," IEEE Trans. Energy Convers., vol. 15, no. 4, pp. 361-365, Dec. 2000.

[4] L. Vido, M. Gabsi, M. Lecrivain, Y. Amara, and F. Chabot, "Homopolar and bipolar hybrid excitation synchronous machines," in Proc. IEEE Int. Conf. Elect. Mach. Drives, May 2005, pp. 1212-1218.
[5] B. Nedjar, S. Hlioui, Y. Amara, L. Vido, M. Gabsi, and M. Lecrivain, "A new parallel double excitation synchronous machine," IEEE Trans. Magn., vol. 47, no. 9, pp. 2252-2260, Sep. 2011.

[6] A. Parviainen, M. Niemela, and J. Pyrhonen, "Modeling of axial flux PM machines," in Proc. IEEE Int. Elect. Mach. Drives Conf. (IEMDC), vol. 3. Jun. 2003, pp. 1955-1961.

[7] Y. Yoshida, K. Nakamura, and O. Ichinokura, "A method for calculating eddy current loss distribution based on reluctance network analysis," IEEE Trans. Magn., vol. 47, no. 10, pp. 4155-4158, Oct. 2011.

[8] B. Bekkouche, A. Chaouch, and Y. Mezari, "A switched reluctance motors analyse using permeance network method," Int. J. Appl. Eng. Res., vol. 1, no. 2, pp. 137-152, 2006.

[9] K. Tajima, K. Sato, T. Komukai, and O. Ichinokura, "Reluctance network analysis of an orthogonal-core type parametric induction motor," IEEE Trans. Magn., vol. 35, no. 5, pp. 3706-3708, Sep. 1999.

[10] K. Nakamura and O. Ichinokura, "Dynamic simulation of PM motor drive system based on reluctance network analysis," in Proc. 13th Power Electron. Motion Control Conf. (EPE-PEMC), Sep. 2008, pp. 758-762.

[11] N. Bracikowski, M. Hecquet, P. Brochet, and S. V. Shirinskii, "Multiphysics modeling of a permanent magnet synchronous machine by using lumped models," IEEE Trans. Ind. Electron., vol. 59, no. 6, pp. 2426-2437, Jun. 2012.

[12] J. M. Williams, "Modeling and analysis of electric machines with asymmetric rotor poles using a reluctances based, magnetic equivalent circuit," Ph.D. dissertation, Elect. Comput. Eng., Missouri Univ. Sci. Technol., Rolla, MO, USA, 2004.

[13] E. Ilhan, J. Paulides, L. Encica, and E. Lomonova, "Tooth contour method implementation for the flux-switching PM machines," in Proc. XIX Int. Conf. Electr. Mach. (ICEM), Sep. 2010, pp. 1-6.

[14] V. Ostovic, Dyn saturated machines. New York, NY, USA: Springer-Verlag, 1989.

[15] D. Fodorean, A. Djerdir, I.-A. Viorel, and A. Miraoui, "A double excited synchronous machine for direct drive application-Design and prototype tests," IEEE Trans. Energy Convers., vol. 22, no. 3, pp. 656-665, Sep. 2007.

[16] Z. Q. Zhu, Y. Pang, D. Howe, S. Iwasaki, R. Deodhar, and A. Pride, "Analysis of electromagnetic performance of flux-switching permanentmagnet machines by nonlinear adaptive lumped parameter magnetic circuit model," IEEE Trans. Magn., vol. 41, no. 11, pp. 4277-4287, Nov. 2005.

[17] J. Cale, S. D. Sudhoff, and J. Turner, "An improved magnetic characterization method for highly permeable materials," IEEE Trans. Magn., vol. 42, no. 8, pp. 1974-1981, Aug. 2006.

[18] D. A. Staton, W. L. Soong, and T. J. E. Miller, "Unified theory of torque production in switched reluctance and synchronous reluctance motors," IEEE Trans. Ind. Appl., vol. 31, no. 2, pp. 329-337, Mar. 1995.

[19] R. P. Deodhar, D. A. Staton, T. M. Jahns, and T. J. E. Miller, "Prediction of cogging torque using the flux-mmf diagram technique," in Proc. IEEE Ind. Appl. Conf. 30th IAS Annu. Meeting, (IAS) Conf. Rec., vol. 1. Oct. 1995, pp. 693-700.

K. Hoang received the M.S. degree in electrical engineering from the Korea Electrotechnology Research Institute, University of science and technology, Daejeon, South Korea, in 2011. He is currently pursuing the Ph.D. degree with the Systèmes et Applications des Technologies de l'Information et de l'Energie, École normale supérieure de Cachan, Cachan, France.

His current research interests include machine design and optimization.

L. Vido received the M.S. and Ph.D. degrees from École normale supérieure de Cachan, Cachan, France, in 2001 and 2004, respectively.

Since 2005, he has been an Associate Professor with the Universite de Cergy-Pontoise, Cergy, France. He is currently with the Systèmes et Applications des Technologies de l'Information et de l'Energie Laboratory, Centre National de la Recherche Scientifique, École normale supérieure de Cachan, Cachan, France, and University Paris Sud, Orsay, France. His current research interests include the design, modeling and control of new hybrid machines, and novel permanent-magnet machines for automotive applications. 
M. Gabsi received the Ph.D. degree from the University of Paris 6, Paris, France, in 1987, and the Habilitation 'a Diriger des Recherches degree from the University of Paris 11, Orsay, France, in 1999.

Since 1990, he has been with the Systèmes et Applications des Technologies de l'Information et de l'Energie Laboratory, École normale supérieure de Cachan, Cachan, France. Since 2008, he has been a Full Professor of Electrical Engineering with the Department of Electronics and Electrical Engineering, École normale supérieure de Cachan. His current research interests include switched reluctance machines, vibration and acoustic-noise, and permanentmagnet machines.
F. Gillon received the Engineer Diploma and Ph.D. degrees from the University of science and technology, Lille, France, in 1992 and 1997, respectively.

$\mathrm{He}$ has been an Assistant professor with Ecole Centrale de Lille Villeneuve-d'Ascq, France, since 1999. His current research interests include the design by optimization of electric system and the study of electrical machines for applications such as linear, axial and radial synchronous motors, and railway propulsion system. 